\title{
Alcohol use disorder: pathophysiology, effects, and pharmacologic options for treatment
}

\author{
This article was published in the following Dove Press journal: \\ Substance Abuse and Rehabilitation \\ 23 January 2014 \\ Number of times this article has been viewed
}

\author{
Robin C Wackernah' \\ Matthew J Minnick' \\ Peter Clapp ${ }^{2}$ \\ 'Department of Pharmacy Practice, \\ ${ }^{2}$ Department of Pharmaceutical \\ Sciences, School of Pharmacy, \\ Rueckert-Hartman College for Health \\ Professions, Regis University, \\ Denver, CO, USA
}

\begin{abstract}
Alcohol use disorders (AUD) continue to be a concerning health issue worldwide. Harmful alcohol use leads to 2.5 million deaths annually worldwide. Multiple options exist for the management of dependence on alcohol, not all of which are approved by drug-regulating agencies. Current practice in treating AUD does not reflect the diversity of pharmacologic options that have potential to provide benefit, and guidance for clinicians is limited. Few medications are approved for treatment of AUD, and these have exhibited small and/or inconsistent effects in broad patient populations with diverse drinking patterns. The need for continued research into the treatment of this disease is evident in order to provide patients with more specific and effective options. This review describes the neurobiological mechanisms of AUD that are amenable to treatment and drug therapies that target pathophysiological conditions of AUD to reduce drinking. In addition, current literature on pharmacologic (both approved and nonapproved) treatment options for AUD offered in the United States and elsewhere are reviewed. The aim is to inform clinicians regarding the options for alcohol abuse treatment, keeping in mind that not all treatments are completely successful in reducing craving or heavy drinking or increasing abstinence.
\end{abstract}

Keywords: abuse, alcohol, alcoholism, craving, dependence, relapse

\section{Introduction}

Alcoholic beverages are consumed around the world as an acceptable part of many recreational and ceremonial activities. Low-to-moderate use of alcohol may facilitate socialization, as it reduces anxiety and has a disinhibiting effect on social behaviors. Compared to other drugs of abuse, relatively large amounts of alcohol are required to produce physiological effects. Consider that the average drink contains 14 grams of ethanol, ${ }^{1}$ whereas a tobacco cigarette or a tablet of oxycodone hydrochloride contains only milligram quantities of the active substance. The US National Institute on Alcohol Abuse and Alcoholism defines "heavy drinking" as consuming more than four drinks a day or 14 drinks a week for males, and consuming more than three drinks a day or seven drinks a week for females. It is estimated that one in four heavy drinkers have alcohol-related problems, such as dependence. ${ }^{1}$

Addiction treatment trials often use the Diagnostic and Statistical Manual of Mental Disorders (Text Revision), 4th edition (DSM-IV-TR) definition of alcohol use disorders ([AUD] abuse or dependence) to define study participants. The DSM-IV definition of alcohol dependence requires significantly harmful impact caused by at least three out of seven target conditions within a single year. These dependence symptoms include tolerance; withdrawal; increased amounts of alcohol consumed
Correspondence: Peter Clapp

Regis University, Rueckert-Hartman College for Health Professions, School of Pharmacy, 3333 Regis Blvd, H-28,

Denver, CO 8022I-1099, USA

$\mathrm{Tel}+\mathrm{I} 303625$ I3 I2

Fax +I 303625 I305

Email pclapp@regis.edu 
over time; ineffective efforts to reduce use; interference with personal or professional life; significant amount of time spent obtaining, using, and recovering from alcohol; or continued use of alcohol despite harmful sequelae. ${ }^{2}$ Alcohol abuse is defined broadly and requires the presence of at least one of the four abuse criteria for diagnosis.

The DSM-5, which was released in May 2013, has combined criteria for alcohol dependence and abuse into a single term (AUD). Craving was added as a diagnostic criteria and at least two target conditions are now required for diagnosis of AUD. ${ }^{3}$ New International Statistical Classification of Diseases and Related Health Problems (ICD) 10 codes that correspond to DSM-5 will be used beginning in October 2014. The majority of clinical trials in this review include subjects with DSM-IV alcohol dependence diagnosis.

Although approved pharmacologic treatment options for patients with AUD are limited in number, recent trials describe a host of alternative approaches to reducing alcohol consumption. These include the use of antipsychotics, antidepressants, anticonvulsants, and others, under the rationale that these drugs target the neurotransmitter systems that have been shown to undergo changes with chronic exposure to alcohol. This review describes current evidence for the clinical use of a broader range of pharmacotherapies in AUD, along with available information on patient characteristics (eg, genetic, demographic, behavioral) that may predict positive outcomes of treatment.

\section{Methods}

Clinical trials associated with alcohol abuse or dependence were identified using PubMed, Ovid, Cochrane Library, and MEDLINE. Search terms included "alcohol abuse," "alcoholism," "antipsychotics," "antidepressants," "anticonvulsants," and "treatments for alcohol use disorders" through October 2013. Articles that focus on alcohol detoxification and managing alcohol withdrawal syndrome were excluded, as this topic is outside the scope of this review. Medications within and outside the United States are included in this review. Only articles available in English are included. Studies using dual diagnosis, articles older than 10 years, uncontrolled trials, and review articles were excluded, except where noted.

\section{Neurobiology and pathophysiology of AUD}

The acute and chronic effects of alcohol on brain physiology have been well studied and help to rationalize the investigation of psychotropic drugs in the treatment of AUD.
In particular, neurotransmitter pathways involved in learning and reward have proven to be effective targets, based on the mechanisms of action of two currently approved AUD drugs, acamprosate and naltrexone. Other compounds under current investigation similarly produce effects by targeting monoamine (eg, serotonin [5-HT], norepinephrine, dopamine) or amino acid (eg, glutamate, $\gamma$-aminobutyric acid [GABA]) neurotransmitters.

\section{Alcohol neuroadaptation and reward}

Alcohol, like other addictive drugs, stimulates release of the neurotransmitter dopamine from cells originating in a region of the brain called the ventral tegmental area (VTA). ${ }^{4}$ The VTA is a component of a neuronal circuit called the mesolimbic dopamine system that has been associated with behavioral motivation and reward. Following exposure to alcohol, dopamine released into the nucleus accumbens (NAc) and prefrontal cortex has been postulated to reinforce drinking behaviors or make the experience of drinking more salient. Recent reviews of the neurobiological literature have described evidence that neuronal plasticity and metaplasticity in the mesolimbic system can promote reward-based learning and the development of addiction. ${ }^{5}$ Whereas alcohol does not appear to selectively bind dopamine receptors, its effects on dopamine release are likely mediated through interactions with other neurotransmitter systems, such as glutamate, GABA, corticotropin-releasing factor, and 5-HT, as well as through interactions with the endogenous opioid system (eg, endorphins, enkephalins). ${ }^{6}$

Electrochemical activation of neurons is controlled by a balance between excitatory and inhibitory neurotransmitters. Acutely, alcohol inhibits the flow of ions through N-methylD-aspartate (NMDA)-type glutamate receptors and enhances the activity of GABA receptor channels, producing an overall inhibitory effect on neurons. ${ }^{7}$ Chronic exposure to alcohol promotes neuroadaptive responses that increase the potential excitability of neurons through upregulation or trafficking of NMDA receptors. ${ }^{8}$ Changes in glutamate signaling pathways associated with chronic exposure to alcohol may enhance the response to cues associated with drinking. Plasticity at glutamatergic synapses on dopamine neurons exists in many forms and may regulate how efficiently drug-related events and actions affect vulnerability to developing addiction. ${ }^{5}$ Furthermore, changing the balance between glutamate and GABA signaling establishes a state of hyperexcitability that is manifest upon cessation of drinking and that may contribute to the negative symptoms of alcohol withdrawal. ${ }^{9}$ Changes in the GABA system contribute to the anxiogenic and aversive 
effects of alcohol withdrawal and can persist over long periods of abstinence from alcohol. The desire to relieve anxiety and negative sensations of withdrawal can contribute to relapse to drinking and lead to the repetitive and compulsive behaviors that characterize alcohol dependence. ${ }^{9}$

Pharmacologic strategies to reduce drinking in patients with AUD may attempt to correct the imbalance between excitatory and inhibitory pathways, and relieve the intense craving for alcohol brought about by neuroadaptation. Alternatively, compounds that target reward pathways may compensate for the plasticity in dopamine signaling that enhances the drinking experience of patients with AUD.

In spite of increasing knowledge of the neurobiological disturbances caused by habitual drinking, a common etiological cause for AUD has not been established. Furthermore, the complex interplay of genetic and environmental factors predisposing an individual to the development of AUD exacerbates the search for pharmacologic treatment options that are generally effective across patient populations. ${ }^{10}$

\section{Pathophysiological consequences of alcohol use}

Even in otherwise healthy individuals, alcohol is toxic to most organ systems at doses above one to two drinks per day. ${ }^{11}$ Long-term exposure to alcohol generally increases the risk of damage to the gastrointestinal, cardiovascular, immune, nervous, and other systems. Cellular toxicity can be initiated by the metabolism of ethanol and subsequent accumulation of acetaldehyde, a metabolite that can damage intracellular proteins and induce cell death through apoptosis. ${ }^{11}$ Additionally, changes in the oxidation-reduction state of a cell following substantial ethanol metabolism can have an impact on cellular respiration and the metabolism of fats in both animals and humans. ${ }^{12}$

Alcohol can promote gastrointestinal bleeding through inflammation of the esophagus and stomach, or through vomiting that can damage the gastrointestinal mucosa. Acute pancreatitis is more prevalent in alcoholics than in the general population and can progress to chronic disease or pancreatic cancer with prolonged exposure. ${ }^{13}$ Accumulation of fat in the liver as a result of decreased oxidation of fatty acids and other metabolic changes can progress to fatty liver disease, alcohol-induced hepatitis, and cirrhosis. ${ }^{14}$

Low-to-moderate alcohol consumption (one to two drinks per day) causes peripheral vasodilation and decreases contractility of the heart, resulting in a mild decrease in blood pressure. ${ }^{15}$ Changes in clotting mechanisms or increases in high-density lipoprotein in alcohol users who typically have one drink per day may even confer a cardioprotective effect. ${ }^{16}$ However, consuming three or more drinks per day is a factor in mild-to-moderate hypertension and heavy drinkers are at increased risk for coronary artery disease and cardiomyopathy. The effects of heavy drinking can range from left ventricular impairment and arrhythmia to heart failure as a result of limited contractility of heart muscle. Binge drinking (eg, a single exposure to $90 \mathrm{~mL}$ of 80 -proof whiskey) can produce atrial or ventricular arrhythmias, even in individuals who have no other evidence of heart disease, a syndrome known as "holiday heart."17

Alcohol-dependent individuals may experience peripheral neuropathy characterized by tingling or numbness, especially in the hands and feet. A progressive neurologic syndrome that affects gait and stance, often accompanied by nystagmus, can result from atrophy of the cerebellum due to alcohol toxicity. ${ }^{18}$ Less common are neurologic syndromes that result from thiamine deficiency secondary to heavy drinking: Wernicke's syndrome consists of encephalopathy, uncoordinated muscle movement, and eye muscle weakness; and Korsakoff's syndrome is characterized by amnesia.

\section{Demographics of alcohol use}

Consumption of alcoholic beverages in the US is common, with two-thirds of adults over 18 years of age having consumed alcoholic beverages within the past year, according to the 2011 National Health Interview survey. ${ }^{19}$ The highest prevalence of heavy use (13.7\%) is observed in the age group from 18 to 25 years. ${ }^{20}$ Estimates in the general population are similar or higher in Europe, according to the World Health Organization. $^{21}$

Severe repetitive problems with alcohol are reported to have a lifetime risk in men of almost $20 \%$ and in women of $10 \%-15 \% .^{22}$ Annual costs associated with health and productivity problems caused by heavy drinking have been estimated to be $\$ 185$ billion in the US in recent years, and this substance contributes to hundreds of thousands of deaths annually in the US (ie, 2.1 deaths per 100,000) and across Europe. ${ }^{20,21}$ Because of alcohol's adverse effects on several physiological systems and interactions with many therapeutic medications, medical management and patient care is greatly impacted by modern, heavy levels of alcohol consumption. $^{23}$

\section{Pharmacotherapy: approved medications for AUD}

Pharmacologic strategies for treating alcohol dependence include generating an aversive physiological reaction to 
alcohol to mask positive subjective effects and administering medications that block alcohol reinforcement. Medications that target the reward pathways in the brain have been suggested to normalize adaptations to chronic alcohol exposure and reduce craving for alcohol. ${ }^{7}$ Other strategies aim to reduce negative symptoms of alcohol withdrawal that may promote relapse drinking by restoring the balance between inhibitory and excitatory neurotransmitter pathways. ${ }^{7}$ Three medications are currently approved by the US Food and Drug Administration for the treatment of alcohol dependence in adults: disulfiram, acamprosate, and naltrexone. Nalmefene is approved for alcohol dependence in Europe.

\section{Disulfiram}

The primary pharmacologic action of disulfiram involves the disruption of normal alcohol metabolism. After ethyl alcohol is absorbed by the body, it becomes converted to acetaldehyde, which is oxidized in the liver by the mitochondrial enzyme aldehyde dehydrogenase (ALDH) ${ }^{24}$ Disulfiram produces an irreversible inhibition of ALDH activity. When alcohol is ingested after taking disulfiram, acetaldehyde can accumulate to concentrations that are five to ten times higher than those found after consuming alcohol alone. The accumulation of acetaldehyde leads to unpleasant physiologic reactions including nausea, vomiting, flushing, rapid heartbeat, and falling blood pressure that deter continued drinking. The degree of response to the disulfiram-alcohol reaction increases with the dose of disulfiram and blood alcohol concentration, but even small amounts of alcohol consumed with disulfiram can produce mild reactions. ${ }^{24}$

Due to the adverse effects of the ethanol-disulfiram reaction, disulfiram has the greatest potential for benefit in alcohol-dependent patients who are highly motivated to quit drinking. ${ }^{25}$ Patients must set a goal of abstinence when initiating disulfiram therapy, and providers should encourage patients to establish the resources and self-motivation to maintain abstinence once the drug is discontinued. Noncompliance is one of the biggest challenges in the use of disulfiram, illustrated by the $20 \%$ compliance measure in the largest controlled trial to date, administered among male US veterans. ${ }^{26} \mathrm{~A}$ very recent, single-blind trial in Japanese males with AUD demonstrated improved rates of abstinence only among subjects with an inactive $A L D H 2$ allele. ${ }^{27}$ Disulfiram should be used with caution in patients with liver disease due to rare but fatal cases of hepatitis, and it is contraindicated for those with cardiac disease due to hypotension during the disulfiram reaction. ${ }^{28}$

The clinical efficacy of disulfiram to reduce craving and prevent relapse to drinking may be related to changes in neurotransmission. Metabolites of disulfiram can alter neurotransmitter levels in the NAc that are implicated in the response to alcohol, and other studies suggest the acetaldehyde reaction may not be necessary to achieve favorable treatment outcomes. ${ }^{29,30}$

\section{Acamprosate}

Acamprosate has been approved for use in alcohol-dependent individuals since 2004. Acamprosate is structurally similar to the endogenous amino acids (eg, glutamate, GABA, glycine) that act as neurotransmitters or neuromodulators in several different brain regions. ${ }^{31}$ The primary beneficial mechanism of action remains unclear; however, acamprosate is believed to normalize the balance between excitatory and inhibitory pathways that become adapted to chronic alcohol use and alleviate psychological and physiological discomfort that follows withdrawal. These effects may be due to some combination of antagonizing NMDA glutamate receptors, modulating type 5 metabotropic glutamate receptors, or reducing glutamate accumulation during repeated episodes of alcohol withdrawal. ${ }^{31}$

Initial findings from US multisite studies, including the Combined Pharmacotherapies and Behavioral Interventions for Alcohol Dependence (COMBINE) trial, ${ }^{32}$ differed significantly from earlier European trials, showing no benefit for acamprosate when compared to placebo in reducing alcohol use in treatment-seeking alcoholics. ${ }^{33}$ The recent PREDICT trial found no effect of acamprosate in extending time to first heavy drinking day among a predominantly male German patient population that had undergone inpatient treatment prior to enrollment, including an average 18 days of lead-in abstinence. ${ }^{34}$ It is possible that the high percentage of abstinent days across all groups in the COMBINE and PREDICT trials masked any benefit of acamprosate to promote abstinence above the combined behavioral intervention and/or medical management provided to all subjects. Large placebo effects are common in AUD trials, making the demonstration of significant effect sizes difficult. ${ }^{35}$ Primary care patients in the US also failed to benefit from acamprosate treatment, but exhibited a higher percentage of days abstinent during the study if they expressed a goal of abstinence at baseline. ${ }^{36}$ Meta-analysis of the European trial database, consisting primarily of middle-aged males with 7 years or more of dependence on alcohol, confirmed significant improvements in abstinence rates, percent days abstinent, and time to first drink with acamprosate treatment. ${ }^{33}$ Acamprosate also has a favorable safety and tolerability profile. ${ }^{37}$

\section{Naltrexone}

Naltrexone is available for oral or intramuscular administration to reduce the craving for alcohol. The clinical 
efficacy of naltrexone is believed to be mediated through interactions between dopamine and the endogenous opioid neuropeptide systems. ${ }^{8}$ The endogenous opioids are involved in the expression of alcohol's reinforcing effects and may promote drug-seeking behaviors. Naltrexone functions as a competitive antagonist at opioid receptors. In animal models, alcohol administration was shown to promote $\beta$-endorphin release in regions of the brain that are involved in reward..$^{38}$ Relief of the tonic inhibiting effects of GABA neurons by $\beta$-endorphins in the VTA promotes dopaminergic signaling from this area of the brain to the NAc.

Naltrexone is relatively well tolerated, and the primary side effect is gastrointestinal discomfort. High doses have been suggested to increase the risk of hepatotoxicity, and because naltrexone is an antagonist that can precipitate opioid withdrawal syndrome, it is contraindicated in patients who currently use opioid drugs. ${ }^{39}$

In the COMBINE trial, naltrexone demonstrated improvements in maintaining abstinence and reducing heavy drinking, especially in patients who received no behavioral intervention. ${ }^{32}$ Further analyses demonstrated high clinical efficacy in the use of naltrexone with psychotherapy for short treatment periods. ${ }^{40}$ PREDICT failed to show an effect of oral naltrexone on heavy drinking in a patient population with a greater duration of continuous abstinence prior to randomization. ${ }^{34} \mathrm{~A}$ recent multisite investigation of the efficacy of intramuscular naltrexone in a randomized, placebocontrolled trial found $25 \%$ reduction in the event rate of heavy drinking days, especially in males who had achieved 7 days of lead-in abstinence. ${ }^{41} \mathrm{~A}$ secondary analysis revealed naltrexone effects on any drinking and complete abstinence in patients with a more clinically relevant period of 4 days lead-in abstinence. ${ }^{42}$ Direct comparison between oral and intramuscular administration has not been reported.

\section{Nalmefene}

Nalmefene is an opioid receptor modulator that is approved by the Committee for Medicinal Products for Human Use of the European Medicines Agency for use in the European Union. ${ }^{43}$ Nalmefene was approved for marketing in February 2013 and is approved for "the reduction of alcohol consumption in adult patients with alcohol dependence who have a high drinking risk level." ${ }^{43}$ It works in a similar fashion to naltrexone, as an opioid antagonist at $\mu$ and $\delta$ receptors, and as an agonist at $\kappa$ receptors. ${ }^{43}$ It is hypothesized that the blockade of opioid receptors interferes with the reinforcing effects of alcohol, in turn reducing alcohol cravings. ${ }^{38}$
Nalmefene has been recorded to reduce the number of drinks per drinking day in alcohol-dependent subjects; ${ }^{44}$ however, when measuring days abstinent, ${ }^{44,45}$ number of heavy drinking days, ${ }^{45-47}$ time to relapse, ${ }^{44-46}$ and subjective cravings ${ }^{44,47}$ the data are controversial. While nalmefene may be superior to naltrexone in its ability to reduce alcohol cravings, ${ }^{48}$ and does not carry the same hepatotoxicity risk, its role in treating alcohol-dependent patients remains unclear.

\section{Pharmacotherapy: non-approved medications for AUD}

A variety of non-approved medications have been studied in the treatment of AUD. Medications like disulfiram and naltrexone have been associated with hepatic toxicity. This can be an issue with chronic drinking, as alcohol is associated with hepatotoxicity and $55 \%$ of deaths associated with alcohol are the result of liver disease. ${ }^{49}$ Acamprosate should be avoided in patients with severe renal impairment. ${ }^{50}$ Additionally, these medications are not effective in all patients for an indeterminate period of time, ${ }^{51}$ leading clinicians to seek additional options for the treatment of AUD.

Common measurements to determine the efficacy of medications for AUD include: percentage of drinking days; total amount of drinking; relapse; abstinence; cravings; and brain activation in the reward pathways of the brain.

Many published studies of non-approved medications included patients on psychotropic agents (eg, antipsychotics, antidepressants, anticonvulsants), suggesting the presence of a comorbid psychiatric illness and dual diagnosis of AUD with a mood or thought disorder. Dual diagnosis is an important and challenging issue, which can, however, introduce a number of variables that can lead to relapse. Clinical trials in patients with uncontrolled comorbid psychiatric diagnoses are not included in this review but can be found in other publications. ${ }^{52,53}$

\section{Antipsychotics}

Antipsychotics are used for the treatment of schizophrenia and bipolar disorder and as adjunctive treatment for depression and autism. They block various dopamine receptors, and the second-generation antipsychotics are unique in that they also block $5-\mathrm{HT}_{2}$ receptors. Due to dopamine's implication in the reward pathways associated with AUD, these medications are targets for current research.

\section{Aripiprazole}

Aripiprazole at higher doses (23.3 mg daily) may be helpful in reducing number of drinks per day ${ }^{54}$ and reducing urges after follow-up drinks (15 mg daily) ${ }^{55}$ however, when 
measuring number of heavy drinking days, days abstinent, ${ }^{54}$ and subjective craving, ${ }^{56}$ aripiprazole performed poorly against placebo. Despite objective evidence that ventral striatum activation is blunted with aripiprazole, ${ }^{56}$ and that aripiprazole may be as efficacious as naltrexone in reducing craving and increasing time to relapse in patients with a goal of abstinence, ${ }^{57}$ its precise usefulness in alcohol-dependent patients is not clear.

\section{Olanzapine}

Olanzapine reduced alcohol cravings in young adult subjects (23 years average age) $)^{58}$ and reduced the number of drinks per day in AUD patients with higher baseline drinking habits, ${ }^{59,60}$ but only in individuals with the long version of the $\mathrm{D} 4$ dopamine receptor gene (DRD4). When studied in patients with no DRD4 allele stratification, 5-15 mg daily for 12 weeks was not different from placebo in reducing drinking measures. ${ }^{61}$ Given the minimal use of genetic information in AUD patient assessment, olanzapine may be considered on a trial-and-error basis in AUD.

\section{Quetiapine}

Quetiapine $400 \mathrm{mg}$ daily for 6 weeks has shown positive results in drink reduction and impulsivity ${ }^{62}$ and, over 12 weeks, demonstrated reduced drinking in type B alcoholics (early onset, more severe) compared to type A alcoholics (late onset, less severe). ${ }^{63}$ Quetiapine may not be useful in very heavy drinkers ${ }^{64}$ or as an adjunct to naltrexone, ${ }^{65}$ but may be an option to reduce drinking in less heavy drinkers or type B alcoholics.

\section{Other antipsychotics (flupenthixol,} amisulpride, and tiapride)

Flupenthixol intramuscular injection, ${ }^{66,67}$ amisulpride, ${ }^{68}$ and tiapride ${ }^{69}$ all performed poorly in placebo-controlled studies on measures of alcohol intake, craving, and abstinence.

\section{Antidepressants}

The majority of antidepressants studied in alcohol dependence use selective 5-HT reuptake inhibitors (SSRIs). These work by blocking the reuptake of 5-HT, allowing increased agonism of 5-HT receptors. 5-HT agonists have shown reduction in alcohol consumption in animal studies, ${ }^{70}$ and, due to these findings, may be a future option for AUD treatment.

\section{Citalopram}

Citalopram $40 \mathrm{mg}$ has been found to reduce alcohol consumption in moderate drinkers, ${ }^{71}$ particularly in men $;{ }^{72}$ however, this effect did not carry over to very heavy drinkers. ${ }^{73}$ Potential lack of efficacy in very heavy drinking was further illustrated when subjects with lower baseline average daily drinking had $50 \%$ or more reduction in baseline drinking with citalopram $40 \mathrm{mg}$ compared to subjects with higher daily drinking averages. ${ }^{74}$

\section{Sertraline}

Sertraline $200 \mathrm{mg}$ daily has been found to reduce drinking behaviors in type A alcoholic men; ${ }^{75}$ these results were not seen in type B alcoholic men or women. ${ }^{76}$ Sertraline's efficacy in less severe alcohol dependence was again replicated in late-onset/low-vulnerability alcoholics who were homozygous for the long allele of the 5-HT transporter. ${ }^{77}$

Its effectiveness as an adjunct to naltrexone is not clear. Trials that evaluated sertraline as adjunctive therapy to naltrexone used $100 \mathrm{mg},{ }^{78,79}$ compared to other trials where $200 \mathrm{mg}$ was used when sertraline was tested as monotherapy in AUD. ${ }^{75-77}$

\section{Fluoxetine}

Fluoxetine lacks consistent evidence for its usefulness in alcohol dependence. In undiagnosed alcohol-dependent patients, $60 \mathrm{mg}$ daily of fluoxetine reduced total and daily drinks $^{80}$ and significantly reduced craving compared to baseline, but not to placebo; ${ }^{81}$ however, $60 \mathrm{mg}$ did not affect abstinence $^{80}$ or relapse rates in very heavy drinkers (average 18.6 drinks/day), ${ }^{82}$ nor reduce daily baseline or drinks per drinking day when compared to placebo. ${ }^{81}$ When dosed at $40 \mathrm{mg}$, fluoxetine did not reduce intake levels. ${ }^{80}$ At higher doses of $80 \mathrm{mg}$, daily fluoxetine reduced alcohol intake the initial week of a 4 -week study. ${ }^{83}$

\section{Anticonvulsants}

Anticonvulsants are used for seizure disorders and several have indications for chronic pain conditions and mood stabilization. They have a variety of mechanisms, including blockage of sodium channels, enhancing GABA, antagonizing glutamate receptors, and blocking calcium channels.

\section{Gabapentin}

Gabapentin titrated to 1,200 mg daily reduced craving after an alcohol cue,${ }^{84}$ increased days abstinent in subjects with more severe alcohol withdrawal, reduced relapse to heavy drinking in patients with insomnia, ${ }^{85}$ and improved other drinking measures. ${ }^{86}$ Gabapentin $600 \mathrm{mg}$ daily found positive benefits in very heavy drinkers. ${ }^{86}$ As an adjunct to naltrexone, gabapentin reduced total drinking and urges. ${ }^{87}$ Reduction in craving was not found in a real-world design amount of drinking. ${ }^{88}$ 


\section{Topiramate}

In placebo-controlled, blinded studies using target doses of topiramate of $300 \mathrm{mg}$ daily, topiramate outperformed placebo in multiple drinking measure ${ }^{89-91}$ and craving. ${ }^{91}$ Topiramate was equivalent to naltrexone in a blinded design measuring relapse and abstinence. ${ }^{92}$ Craving ${ }^{93}$ and intake ${ }^{94}$ were superior in naturalistic open designs.

Topiramate $150 \mathrm{mg}$ daily was compared to disulfiram in a non-blinded randomized study. The study found disulfiram to be superior in abstinence and daily drinks, while topiramate significantly reduced craving compared to disulfiram; ${ }^{95}$ the lack of blinding and the low dose of topiramate, however, suggests that a more robust design with adequate topiramate dosing is warranted before drawing strong conclusions regarding the superiority of either medication. Topiramate can also be considered an effective adjunctive therapy in lower doses ( $75 \mathrm{mg}$ daily) when combined with psychotherapy for alcohol dependence. ${ }^{96}$

\section{Levetiracetam}

An open-label trial with levetiracetam on alcohol dependence found positive results; ${ }^{97}$ however, double-blind, placebocontrolled trials failed to find a benefit of levetiracetam for alcohol dependence. ${ }^{98,99}$ One study found that moderate-toheavy drinkers taking levetiracetam increased their drinking during the study period. ${ }^{100}$

\section{Oxcarbazepine}

Oxcarbazepine has been shown to be equivalent in efficacy to acamprosate ${ }^{101}$ and naltrexone ${ }^{102}$ in open-label studies comparing time to first relapse. At higher doses, $1,500-1,800 \mathrm{mg}$ daily, oxcarbazepine was superior to naltrexone in a number of patients who remained alcohol-free. ${ }^{102}$ There are currently no placebo-controlled blinded studies testing oxcarbazepine's place in alcohol dependence.

\section{Divalproex sodium (VPA)}

VPA significantly decreased relapse to heavy drinking in a blinded study against placebo and also decreased amount of drinking and craving compared to baseline. ${ }^{103} \mathrm{~A}$ small nonblinded study found VPA treatment increased abstinence at 6 weeks post-detoxification, though this was not statistically significant. ${ }^{104}$

\section{Other anticonvulsants (carbamazepine zonisamide, tiagabine, pregabalin)}

Carbamazepine and zonisamide have placebo-controlled trials supporting their potential use in alcohol dependence. ${ }^{105,106}$
Zonisamide was significantly better than placebo in reducing number of heavy drinking days, reduction in number of drinks per week, and urge to drink. Days abstinent were similar to placebo. ${ }^{105}$ Similarly, carbamazepine outperformed placebo in longer time to relapse to heavy drinking. ${ }^{106}$

Tiagabine ${ }^{107}$ and pregabalin ${ }^{108}$ both have open-label trials supporting their potential usefulness in alcohol dependence; however, placebo-controlled and head-to-head trials are needed to ascertain their particular place in therapy.

\section{Other off-label medications}

\section{Ritanserin}

Ritanserin is a $5-\mathrm{HT}_{2}$ receptor antagonist with documented use to improve sleep, mood, and vigilance. ${ }^{109}$ The feedback inhibition of dopaminergic activity related to blocking 5-HT receptors may act as a substitute for alcohol effects. ${ }^{110}$

Multiple large clinical trials revealed poor results with ritanserin when compared to placebo when measuring daily drinks, craving in heavy drinkers, ${ }^{110,111}$ and relapse rates. ${ }^{112}$

\section{Baclofen}

Baclofen is a skeletal muscle relaxant that is approved for use in muscle spasticity. It is a GABA-B agonist and, through this mechanism, the dopaminergic response to alcohol may be inhibited. ${ }^{113}$

In addition to a 12 -week open-label study ${ }^{114}$ baclofen $30 \mathrm{mg}$ daily has shown positive benefit compared to placebo in abstinence, ${ }^{115-117}$ craving, and daily alcohol intake. ${ }^{115}$ Higher doses $(60 \mathrm{mg} /$ day) produced a more robust response in reduction of number of drinks per day compared to $30 \mathrm{mg}$ daily. ${ }^{118}$ Studies that failed to replicate the benefits of baclofen used patients with a lower daily drink intake and no comorbid liver problems who were recruited via advertisements, ${ }^{119}$ as opposed to subjects seeking treatment.

\section{Ondansetron}

Ondansetron is an antiemetic medication that blocks $5-\mathrm{HT}_{3}$ receptors. Due to alcohol's activity on $5-\mathrm{HT}_{3}$, it is thought that ondansetron can be a useful medication in alcohol dependence. ${ }^{120}$

Ondansetron has been studied in four blinded placebo-controlled trials comparing low doses for alcohol dependence. Ondansetron significantly reduced daily drinking in light drinkers. No benefit was seen in heavy drinkers (>10 drinks/day). ${ }^{121}$ Additional studies using weight-based dosing found benefits in craving, ${ }^{122}$ abstinence, and total drinks. ${ }^{123}$ One study showed increase in craving but reduced drinks per day. When used with naltrexone ondansetron, 
$0.5 \mathrm{mg}$ reduced cue-induced craving and activation of the ventral striatum. ${ }^{124}$

\section{Prazosin}

Prazosin is an alpha 1-receptor adrenergic blocker that is used for the treatment of hypertension. ${ }^{125}$ At a titrated target dose of $16 \mathrm{mg}$ daily, prazosin has been shown to reduce stress-induced craving, ${ }^{126}$ drinks per weeks, and drinking days. ${ }^{125}$ Simpson et al did not see a reduction in craving, though craving was not stress elicited. ${ }^{125}$

\section{Varenicline}

Varenicline is a nicotine agonist used for smoking cessation. ${ }^{127}$ Varenicline reduced number of drinks consumed, abstinence, and craving after a priming drink in a 2-hour session in smokers with AUD. ${ }^{127}$ It also reduced number of drinks per week and craving in a 16-week trial, but did not have an effect on total days abstinent. ${ }^{128}$

\section{Kudzu extract}

The kudzu root has been historically studied for its use in alcoholism; of particular interest are the extracts of the plant. The mechanism is not fully understood, but it is proposed that the extracts of the kudzu root may alter alcohol dehydrogenase or monoamine oxidase-acetaldehyde pathways, ${ }^{129,130}$ leading to reduced alcohol consumption.

Kudzu root extract was studied in non-treatment-seeking male drinkers over the course of a 4-week period. When compared to placebo, the kudzu extract reduced weekly alcohol consumption and increased the amount of consistent abstinent days. ${ }^{130}$ Additionally, puerarin (one of the three main isoflavones of the kudzu root) was found to reduce the amount of beer consumed when compared to placebo in non-diagnosed heavy drinkers. ${ }^{129}$ Both studies, however, indicate that the kudzu extract did not reduce subjective alcohol cravings, ${ }^{129,130}$ which may limit clinical use. The kudzu root extract appears to be beneficial in lowering alcohol consumption in heavy drinkers.

\section{Conclusion}

Disulfiram, naltrexone, acamprosate, and nalmefene all have benefits in the treatment of AUD. Considering the potential for treatment failure with approved pharmacological options or the inability to use a medication due to comorbid health conditions, a number of medications have been studied in AUD. For example, in the presence of a failed response to naltrexone or a contraindication (current opioid withdrawal) to its use, aripiprazole ${ }^{57}$ and topiramate ${ }^{92}$ both appear to be equal to naltrexone in efficacy for AUD. Perhaps the continued exploration of non-approved medications will result in the identification of a drug or combination of drugs that demonstrates generalized effectiveness in all AUD patient types.

Alternatively, heterogeneity of AUD patients and the complex etiology of the disease may preclude the discovery of such a drug. Varying patterns of consumption and differences in onset of drinking have defined AUD patient subtypes that respond differently to pharmacotherapy. Reported outcomes in subpopulations of study cohorts have followed a range of demographics, including sex and genetic background. Recognizing trends in current reports and strengthening associations between AUD subtypes and treatment outcomes with new studies may provide clinical guidance to prescribers in the near future. For example, an individual's drinking goal (eg, controlled drinking, conditional abstinence, complete abstinence) established prior to treatment has been shown to be highly associated with clinical outcome, validating the importance of patient motivation for behavioral change. ${ }^{131}$ Clinical outcomes and drinking behavior just prior to treatment have also been shown to associate with medication effect. Acamprosate is slightly more efficacious in promoting abstinence than naltrexone, and it has a larger effect size in patients who have undergone detoxification. ${ }^{132}$ Naltrexone is slightly more efficacious in reducing heavy drinking than acamprosate, and it is associated with a larger medication effect in patients who enter treatment after a period of lead-in abstinence. ${ }^{132}$ Therefore, a patient's drinking goals and current drinking status, as well as the intended clinical outcome, should be determined prior to treatment.

With regard to sex, although women with AUD enter treatment earlier in the course of the disease than men, ${ }^{133}$ clinical studies of pharmacologic AUD treatment tend to be comprised of mostly male patient populations. Treatment responses have been suggested in some cases to be better in men than women (eg, naltrexone, ${ }^{41}$ citalopram, ${ }^{72}$ and sertraline ${ }^{75}$ ), but a recent meta-analysis of over 50 naltrexone and acamprosate trials found no effect of sex on response to treatment. ${ }^{35}$ Although flupenthixol decanoate increased relapse rates among AUD patients, the risk was significantly lower in women than in men. ${ }^{67}$ Further AUD treatment studies that separate male and female populations are warranted.

Other examples of patient-specific criteria that might guide clinical decisions include the use of gabapentin in patients with comorbid insomnia, ${ }^{85}$ prazosin in patients who drink secondary to a stress response, ${ }^{126}$ and varenicline in patients who smoke, ${ }^{127,128}$ and data suggest olanzapine's 
usefulness in patients with genetic predispositions related to the dopamine receptor gene. ${ }^{58}$

The influence of genetic background on patient response has been exemplified by the interaction between naltrexone response and polymorphisms in the $\mu$ opioid receptor gene OPRM1. In a review of the studies that included genetic information, Chamorro et al report that AUD patients who carry the A118G allele demonstrate lower rates of relapse to heavy drinking, with no change in abstinence. ${ }^{134}$ Evidence for a genetic influence on treatment response has also been reported for disulfiram, ${ }^{27}$ olanzapine, ${ }^{58}$ and ondansetron. ${ }^{135}$ As genetic testing becomes more cost-effective, it may represent a feasible strategy to tailor AUD treatments to an individual patient's disease. The use of genetic information has become standard practice in other areas of medicine, including anticoagulation and oncology.

Research with well-designed studies will continue to be a necessity in the area of pharmacologic treatment for AUD. Based on the current state of AUD treatment research, it appears unlikely that a single agent or combination regimen will prove to be effective in all patients with AUD. Instead, clinicians may be obligated to match medication strategies to individuals or AUD subtypes, and this approach demands stronger evidence of treatment efficacy in particular patient groups.

\section{Disclosure}

The authors report no conflicts of interest in this work.

\section{References}

1. Alcohol and health [webpage on the Internet]. Bethesda, MD: National Institute on Alcohol Abuse and Alcoholism. Available from: http://www. niaaa.nih.gov/alcohol-health/overview-alcohol-consumption/standarddrink. Accessed August 30, 2013.

2. Diagnostic and Statistical Manual of Mental Disorders (Text Revision), Fourth edition. Washington, DC: American Psychiatric Association; 2000.

3. Diagnostic and Statistical Manual of Mental Disorders, Fifth Edition. Arlington, VA: American Psychiatric Association; 2013.

4. Kalivas PW, O'Brien C. Drug addiction as a pathology of staged neuroplasticity. Neuropsychopharmacology. 2008;33(1):166-180.

5. Cui C, Noronha A, Morikawa H, et al. New insights on neurobiological mechanisms underlying alcohol addiction. Neuropharmacology. 2013;67:223-232.

6. Lovinger DM, Roberto M. Synaptic effects induced by alcohol. Curr Top Behav Neurosci. 2013;13:31-86.

7. Vengeliene V, Bilbao A, Molander A, Spanagel R. Neuropharmacology of alcohol addiction. Br J Pharmacol. 2008;154(2):299-315.

8. Clapp P, Bhave SV, Hoffman PL. How adaptation of the brain to alcohol leads to dependence: a pharmacological perspective. Alcohol Res Health. 2008;31(4):310-339.

9. Koob GF. Theoretical frameworks and mechanistic aspects of alcohol addiction: alcohol addiction as a reward deficit disorder. Curr Top Behav Neurosci. 2013;13:3-30.

10. Palmer RH, McGeary JE, Francazio S, et. al. The genetics of alcohol dependence: advancing towards systems-based approaches. Drug Alcohol Depend. 2012;125(3):179-191.
11. Guo R, Ren J. Alcohol and acetaldehyde in public health: from marvel to menace. Int J Environ Res Public Health. 2010;7:1285-1301.

12. Manzo-Avalos S, Saavedra-Molina A. Cellular and mitochondrial effects of alcohol consumption. Int J Environ Res Public Health. 2010;7(12):4281-4304.

13. Nitsche C, Simon P, Weiss FU, et al. Environmental risk factors for chronic pancreatitis and pancreatic cancer. Dig Dis. 2011;29(2):235-242.

14. Gao B, Bataller R. Alcoholic liver disease: pathogenesis and new therapeutic targets. Gastroenterology. 2011;141(5):1572-1585.

15. Krenz M, Korthuis RJ. Moderate ethanol ingestion and cardiovascular protection: from epidemiologic associations to cellular mechanisms. J Mol Cell Cardiol. 2012;52(1):93-104.

16. Roerecke M, Rehm J. The cardioprotective association of average alcohol consumption and ischaemic heart disease: a systematic review and meta-analysis. Addiction. 2012;107(7):1246-1260.

17. Greenspon AJ, Schaal SF. The "holiday heart": electrophysiologic studies of alcohol effects in alcoholics. Ann Intern Med. 1983;98(2):135-139.

18. Chopra K, Tiwari V. Alcoholic neuropathy: possible mechanisms and future treatment possibilities. Br J Clin Pharmacol. 2012;73(3): $348-362$.

19. Schiller JS, Lucas JW, Peregoy JA. Summary health statistics for U.S. adults: National Health Interview Survey, 2011. Vital Health Stat. 2012;10(256). Available from: http://www.cdc.gov/nchs/data/series/ sr_10/sr10_256.pdf. Accessed December 18, 2013.

20. Office of Applied Studies. Results from the 2009 National Survey on Drug Use and Health: Volume I. Summary of National Findings. Rockville: Substance Abuse and Mental Health Services Administration; 2010. Available from: http://www.samhsa.gov/data/2k9/2k9Resultsweb/ web/2k9results.pdf. Accessed December 18, 2013.

21. Anderson P, Møller L, Galea G, editors. Alcohol in the European Union: Consumption, Harm and Policy Approaches. Copenhagen: World Health Organization Regional Office for Europe; 2012. Available from: http:// www.euro.who.int/_data/assets/pdf_file/0003/160680/e96457.pdf. Accessed August 30, 2013.

22. Hasin DS, Stinson FS, Ogburn E, Grant BF. Prevalence, correlates, disability, and comorbidity of DSM-IV alcohol abuse and dependence in the United States: results from the National Epidemiologic Survey on Alcohol and Related Conditions. Arch Gen Psychiatry. 2007;64(7): 830-842.

23. Rehm J, Room R, Monteiro M, et al. Alcohol as a risk factor for global burden of disease. Eur Addict Res. 2003;9(4):157-164.

24. Johansson B. A review of the pharmacokinetics and pharmacodynamics of disulfiram and its metabolites. Acta Psychiatr Scand Suppl. 1992;369: $15-26$.

25. Weiss RD, Cogley C. Pharmacotherapy of alcohol dependence: how and when to use disulfiram and naltrexone. Curr Psychiatr. 2002;1(2): $51-60$.

26. Fuller RK, Branchey L, Brightwell DR, et al. Disulfiram treatment of alcoholism: A Veterans Administration cooperative study. JAMA. 1986;256(11):1449-1455.

27. Yoshimura A, Kimura M, Nakayama H, et al. Efficacy of disulfiram for the treatment of alcohol dependence assessed with a multicenter randomized controlled trial. Alcohol Clin Exp Res. Epub October 11, 2013.

28. Mutschler J, Dirican G, Gutzeit A, Grosshans M. Safety and efficacy of long-term disulfiram aftercare. Clin Neuropharmacol. 2011;34(5); 195-198.

29. Mutschler J, Dirican G, Funke S, et al. Experienced acetaldehyde reaction does not improve treatment response in outpatients treated with supervised disulfiram. Clin Neuropharmacol. 2011;34(4):161-165.

30. Faiman MD, Kaul S, Latif SA, Williams TD, Lunte CE. S-(N, $\mathrm{N}$-diethylcarbamoyl)glutathione (carbamathione), a disulfiram metabolite and its effect on nucleus accumbens and prefrontal cortex dopamine, GABA, and glutamate: a microdialysis study. Neuropharmacology. 2013;75:95-105.

31. De Witte P, Littleton J, Parot P, Koob G. Neuroprotective and abstinencepromoting effects of acamprosate: elucidating the mechanism of action. CNS Drugs. 2005;19(6):517-537. 
32. Anton RF, O'Malley SS, Ciraulo DA, et al; COMBINE Study Research Group. Combined pharmacotherapies and behavioral interventions for alcohol dependence: the COMBINE study: a randomized controlled trial. JAMA. 2006;295(17):2003-2017.

33. Kranzler HR, Gage A. Acamprosate efficacy in alcohol-dependent patients: summary of results from three pivotal trials. Am J Addict. 2008;17(1):70-76.

34. Mann K, Lemenager T, Hoffmann S, et al; The PREDICT Study Team. Results of a double-blind, placebo-controlled pharmacotherapy trial in alcoholism conducted in Germany and comparison with the US COMBINE study. Addict Biol. Epub December 12, 2012.

35. Litten RZ, Castle IJ, Falk D, et al. The placebo effect in clinical trials for alcohol dependence: an exploratory analysis of 51 naltrexone and acamprosate studies. Alcohol Clin Exp Res. Epub July 24, 2013.

36. Berger L, Fisher M, Brondino M, et al. Efficacy of acamprosate for alcohol dependence in a family medicine setting in the United States: a randomized, double-blind, placebo-controlled study. Alcohol Clin Exp Res. 2013;37(4):668-674.

37. Yahn SL, Watterson LR, Olive MF. Safety and efficacy of acamprosate for the treatment of alcohol dependence. Subst Abuse. 2013;6:1-12.

38. Gianoulakis C. Alcohol-seeking behavior: the roles of the hypothalamicpituitary-adrenal axis and the endogenous opioid system. Alcohol Health Res World. 1998;22(3):202-210.

39. Vivitrol (naltrexone) [package insert]. Dublin: Alkermes plc; 2010.

40. Jarosz J, Miernik K, Wąchal M, Walczak J, Krumpl G. Naltrexone $(50 \mathrm{mg})$ plus psychotherapy in alcohol-dependent patients: a metaanalysis of randomized controlled trials. Am J Drug Alcohol Abuse. 2013;39(3):144-160.

41. Garbutt JC, Kranzler HR, O'Malley SS, et al. Efficacy and tolerability of long-acting injectable naltrexone for alcohol dependence: a randomized controlled trial. JAMA. 2005;293(13):1617-1625.

42. O'Malley SS, Garbutt JC, Gastfriend DR, Dong Q, Kranzler HR. Efficacy of extended-release naltrexone in alcohol-dependent patients who are abstinent before treatment. J Clin Psychopharmacol. 2007;27(5):507-512.

43. Selincro (nalmefene) [package insert]. Valby: H. Lundbeck A/S; 2013.

44. Mason BJ, Ritvo EC, Morgan RO, et al. A double-blind, placebo-controlled pilot study to evaluate the efficacy and safety of oral nalmefene $\mathrm{HCl}$ for alcohol dependence. Alcohol Clin Exp Res. 1994;18(5):1162-1167.

45. Mason BJ, Salvato FR, Williams LD, Ritvo EC, Cutler RB. A double-blind, placebo-controlled study of oral nalmefene for alcohol dependence. Arch Gen Psychiatry. 1999;56(8):719-724.

46. Anton RF, Pettinati H, Zweben A, et al. A multi-site dose ranging study of nalmefene in the treatment of alcohol dependence. $J$ Clin Psychopharmacol. 2004;24(4):421-428.

47. Karhuvaara S, Simojoki K, Virta A, et al. Targeted nalmefene with simple medical management in the treatment of heavy drinkers: a randomized double-blind placebo-controlled multicenter study. Alcohol Clin Exp Res. 2007;31(7):1179-1187.

48. Drobes DJ, Anton RF, Thomas SE, Voronin K. Effects of naltrexone and nalmefene on subjective response to alcohol among nontreatment-seeking alcoholics and social drinkers. Alcohol Clin Exp Res. 2004;28(9):1362-1370.

49. Schwartz JM, Reinus JF. Prevalence and natural history of alcoholic liver disease. Clin Liver Dis. 2012;16(4):659-666.

50. Campral (acamprosate) [package insert]. St Louis, MO: Forest Pharmaceuticals, Inc; 2012.

51. Bouza C, Angeles M, Muñoz A, Amate JM. Efficacy and safety of naltrexone and acamprosate in the treatment of alcohol dependence: a systematic review. Addiction. 2004;99(7):811-828.

52. Baigent M. Managing patients with dual diagnosis in psychiatric practice. Curr Opin Psychiatry. 2012;25(3):201-205.

53. Murthy P, Chand P. Treatment of dual diagnosis disorders. Curr Opin Psychiatry. 2012;25(3):194-200.

54. Anton RF, Kranzler H, Breder C, Marcus RN, Carson WH, Han J. A randomized, multicenter, double-blind, placebo-controlled study of the efficacy and safety of aripiprazole for the treatment of alcohol dependence. J Clin Psychopharmacol. 2008;28(1):5-12.
55. Voronin K, Randall P, Myrick H, Anton R. Aripiprazole effects on alcohol consumption and subjective reports in a clinical laboratory paradigm - possible influence of self-control. Alcohol Clin Exp Res. 2008;32(11):1954-1961.

56. Myrick H, Li X, Randall PK, Henderson S, Voronin K, Anton RF. The effect of aripiprazole on cue-induced brain activation and drinking parameters in alcoholics. J Clin Psychopharmacol. 2010;30(4): 365-372.

57. Martinotti G, Di Nicola M, Di Giannantonio M, Janiri L. Aripiprazole in the treatment of patients with alcohol dependence: a double-blind, comparison trial vs naltrexone. J Psychopharmacol. 2009;23(2): 123-129.

58. Hutchison KE, Wooden A, Swift RM, et al. Olanzapine reduces craving for alcohol: A DRD4 VNTR polymorphism by pharmacotherapy interaction. Neuropsychopharmacology. 2003;28(10):1882-1888.

59. Hutchison KE, Ray L, Sandman E, et al. The effect of olanzapine on craving and alcohol consumption. Neuropsychopharmacology. 2006;31(6):1310-1317.

60. Hutchison KE, Swift R, Rohsenow DJ, Monti PM, Davidson D, AlmeidaA. Olanzapine reduces urge to drink after drinking cues and a priming dose of alcohol. Psychopharmacology (Berl). 2001;155(1):27-34.

61. Guardia J, Segura L, Gonzalvo B, et al. A double-blind, placebocontrolled study of olanzapine in the treatment of alcohol-dependence disorder. Alcohol Clin Exp Res. 2004;28(5):736-745.

62. Moallem N, Ray LA. Quetiapine improves response inhibition in alcohol dependent patients: a placebo-controlled pilot study. Pharmacol Biochem Behav. 2012;100(3):490-493.

63. Kampman KM, Pettinati HM, Lynch KG, et al. A double-blind, placebocontrolled pilot trial of quetiapine for the treatment of Type A and Type B alcoholism. J Clin Psychopharmacol. 2007;27(4):344-351.

64. Litten RZ, Fertig JB, Falk DE, et al; NCIG 001 Study Group. A doubleblind, placebo-controlled trial to assess the efficacy of quetiapine fumarate $\mathrm{XR}$ in very heavy-drinking alcohol-dependent patients. Alcohol Clin Exp Res. 2012;36(3):406-416.

65. Guardia J, Roncero C, Galan J, Gonzalvo B, Burquete T, Casas M. A double-blind, placebo-controlled, randomized pilot study comparing quetiapine with placebo, associated to naltrexone in the treatment of alcohol-dependent patients. Addict Behav. 2011;36(3):265-269.

66. Wiesbeck GA, Weijers HG, Lesch OM, Glaser T, Toennes PJ, Boening J. Flupenthixol decanoate and relapse prevention in alcoholics: results from a placebo-controlled study. Alcohol Alcohol. 2001;36(4): 329-334.

67. Wiesbeck GA, Weijers HG, Wodarz N, Lesch OM, Glaser T, Boening J. Gender-related differences in pharmacological relapse prevention with flupenthixol decanoate in detoxified alcoholics. Arch Womens Ment Health. 2003;6(4):259-262.

68. Marra D, Warot D, Berlin I, et al. Amisulpride does not prevent relapse in primary alcohol dependence: results of a pilot randomized, placebocontrolled trial. Alcohol Clin Exp Res. 2002;26(10):1545-1552.

69. Bender S, Scherbaum N, Soyka M, Rüther E, Mann K, Gastpar M. The efficacy of the dopamine D2/D3 antagonist tiapride in maintaining abstinence: a randomized, double-blind, placebo-controlled trial in 299 alcohol-dependent patients. Int J Neuropsychopharmacol. 2007;10(5): 653-660.

70. Maurel S, De Vry J, De Beun R, Schreiber R. 5-HT2A and 5-HT2C/5HT1B receptors are differentially involved in alcohol preference and consummatory behavior in cAA rats. Pharmacol Biochem Behav. 1999;62(1):89-96.

71. Naranjo CA, Poulos CX, Bremner KE, Lanctot KL. Citalopram decreases desirability, liking, and consumption of alcohol in alcoholdependent drinkers. Clin Pharmacol Ther. 1992;51(6):729-739.

72. Naranjo CA, Knoke DM, Bremner KE. Variations in response to citalopram in men and women with alcohol dependence. $J$ Psychiatry Neurosci. 2000;25(3):269-275.

73. Balldin J, Berggren U, Engel J, Eriksson M, Hard E, Soderpalm B. Effect of citalopram on alcohol intake in heavy drinkers. Alcohol Clin Exp Res. 1994;18(5):1133-1136. 
74. Naranjo CA, Bremner KE, Bazoon M, Turksen IB. Using fuzzy logic to predict response to citalopram in alcohol dependence. Clin Pharmacol Ther. 1997;62(2):209-224.

75. Pettinati HM, Dundon W, Lipkin C. Gender differences in response to sertraline pharmacotherapy in Type A alcohol dependence. Am J Addict. 2004;13(3):236-247.

76. Pettinati HM, Volpicelli JR, Kranzler HR, Luck G, Rukstalis MR, Cnaan A. Sertraline treatment for alcohol dependence: interactive effects of medication and alcoholic subtype. Alcohol Clin Exp Res. 2000;24(7):1041-1049.

77. Kranzler HR, Armeli S, Tennen H, et al. A double-blind, randomized trial of sertraline for alcohol dependence: moderation by age of onset [corrected] and 5-hydroxytryptamine transporter-linked promoter region genotype. J Clin Psychopharmacol. 2011;31(1):22-30.

78. Farren CK, Scimeca M, Wu R, Malley SO. A double-blind, placebocontrolled study of sertraline with naltrexone for alcohol dependence. Drug Alcohol Depend. 2009;99(1-3):317-321.

79. O’Malley SS, Robin RW, Levenson AL, et al. Naltrexone alone and with sertraline for the treatment of alcohol dependence in Alaska natives and non-natives residing in rural settings: a randomized controlled trial. Alcohol Clin Exp Res. 2008;32(7):1271-1283.

80. Naranjo CA, Kadlec KE, Sanhueza P, Woodley-Remus D, Sellers EM. Fluoxetine differentially alters alcohol intake and other consummatory behaviors in problem drinkers. Clin Pharmacol Ther. 1990;47(4):490-498.

81. Naranjo CA, Poulos CX, Bremner KE, Lanctot KL. Fluoxetine attenuates alcohol intake and desire to drink. Int Clin Psychopharmacol. 1994;9(3):163-172.

82. Kabel DI, Petty F. A placebo-controlled, double-blind study of fluoxetine in severe alcohol dependence: adjunctive pharmacotherapy during and after inpatient treatment. Alcohol Clin Exp Res. 1996;20(4):780-784.

83. Gorelick DA, Paredes A. Effect of fluoxetine on alcohol consumption in male alcoholics. Alcohol Clin Exp Res. 1992;16(2):261-265.

84. Mason BJ, Light JM, Williams LD, Drobes DJ. Proof-of-concept human laboratory study for protracted abstinence in alcohol dependence: effects of gabapentin. Addict Biol. 2009;14(1):73-83.

85. Brower KJ, Myra Kim H, Strobbe S, Karam-Hage MA, Consens F, Zucker RA. A randomized double-blind pilot trial of gabapentin versus placebo to treat alcohol dependence and comorbid insomnia. Alcohol Clin Exp Res. 2008;32(8):1429-1438.

86. Furieri FA, Nakamura-Palacios EM. Gabapentin reduces alcohol consumption and craving: a randomized, double-blind, placebocontrolled trial. J Clin Psychiatry. 2007;68(11):1691-1700.

87. Anton RF, Myrick H, Wright TM, et al. Gabapentin combined with naltrexone for the treatment of alcohol dependence. Am J Psychiatry. 2011;168(7):709-717.

88. Myrick H, Anton R, Voronin K, Wang W, Henderson S. A double-blind evaluation of gabapentin on alcohol effects and drinking in a clinical laboratory paradigm. Alcohol Clin Exp Res. 2007;31(2):221-227.

89. Johnson BA, Ait-Daoud N, Bowden CL, et al. Oral topiramate for treatment of alcohol dependence: a randomised controlled trial. Lancet. 2003;361(9370):1677-1685.

90. Johnson BA, Rosenthal N, Capece JA, et al. Topiramate for treating alcohol dependence: a randomized controlled trial. JAMA. 2007;298(14):1641-1651.

91. Rubio G, Martínez-Gras I, Manzanares J. Modulation of impulsivity by topiramate: implications for the treatment of alcohol dependence. J Clin Psychopharmacol. 2009;29(6):584-589.

92. Baltieri DA, Daró FR, Ribeiro PL, de Andrade AG. Comparing topiramate with naltrexone in the treatment of alcohol dependence. Addiction. 2008;103(12):2035-2044.

93. Flórez G, García-Portilla P, Alvarez S, Saiz PA, Nogueiras L, Bobes J. Using topiramate or naltrexone for the treatment of alcohol-dependent patients. Alcohol Clin Exp Res. 2008;32(7):1251-1259.

94. Flórez G, Saiz PA, García-Portilla P, Alvarez S, Nogueiras L, Bobes J. Topiramate for the treatment of alcohol dependence: comparison with naltrexone. Eur Addict Res. 2011;17(1):29-36.
95. De Sousa AA, De Sousa J, Kapoor H. An open randomized trial comparing disulfiram and topiramate in the treatment of alcohol dependence. J Subst Abuse Treat. 2008;34(4):460-463.

96. Paparrigopoulos T, Tzavellas E, Karaiskos D, Kourlaba G, Liappas I. Treatment of alcohol dependence with low-dose topiramate: an openlabel controlled study. BMC Psychiatry. 2011;11:41.

97. Sarid-Segal O, Piechniczek-Buczek J, Knapp C, et al. The effects of levetiracetam on alcohol consumption in alcohol-dependent subjects: an open label study. Am J Drug Alcohol Abuse. 2008;34(4):441-447.

98. Richter C, Effenberger S, Bschor T, et al. Efficacy and safety of levetiracetam for the prevention of alcohol relapse in recently detoxified alcohol-dependent patients: a randomized trial. J Clin Psychopharmacol. 2012;32(4):558-562.

99. Fertig JB, Ryan ML, Falk DE, et al. A double-blind, placebo-controlled trial assessing the efficacy of levetiracetam extended-release in very heavy drinking alcohol-dependent patients. Alcohol Clin Exp Res. 2012;36(8):1421-1430.

100. Mitchell JM, Grossman LE, Coker AR, Messing RO. The anticonvulsant levetiracetam potentiates alcohol consumption in non-treatment seeking alcohol abusers. J Clin Psychopharmacol. 2012;32(2):269-272.

101. Croissant B, Diehl A, Klein O, et al. A pilot study of oxcarbazepine versus acamprosate in alcohol-dependent patients. Alcohol Clin Exp Res. 2006;30(4):630-635.

102. Martinotti G, Di Nicola M, Romanelli R, et al. High and low dosage oxcarbazepine versus naltrexone for the prevention of relapse in alcohol-dependent patients. Hum Psychopharmacol. 2007;22(3): 149-156.

103. Brady KT, Myrick H, Henderson S, Coffey SF. The use of divalproex in alcohol relapse prevention: a pilot study. Drug Alcohol Depend. 2002;67(3):323-330.

104. Longo LP, Campbell T, Hubatch S. Divalproex sodium (Depakote) for alcohol withdrawal and relapse prevention. J Addict Dis. 2002;21(2): 55-64.

105. Arias AJ, Feinn R, Oncken C, Covault J, Kranzler HR. Placebocontrolled trial of zonisamide for the treatment of alcohol dependence. J Clin Psychopharmacol. 2010;30(3):318-322.

106. Mueller TI, Stout RL, Rudden S, et al. A double-blind, placebocontrolled pilot study of carbamazepine for the treatment of alcohol dependence. Alcohol Clin Exp Res. 1997;21(1):86-92.

107. Paparrigopoulos T, Tzavellas E, Karaiskos D, Malitas P, Liappas I. An open pilot study of tiagabine in alcohol dependence: tolerability and clinical effects. J Psychopharmacol. 2010;24(9):1375-1380.

108. Martinotti G, Di Nicola M, Tedeschi D, Mazza M, Janiri L, Bria P. Efficacy and safety of pregabalin in alcohol dependence. Adv Ther. 2008;25(6):608-618.

109. Wiesbeck GA, Weijers HG, Chick J, Boening J. The effects of ritanserin on mood, sleep, vigilance, clinical impression, and social functioning in alcohol-dependent individuals. Ritanserin in alcoholism work group. Alcohol Alcohol. 2000;35(4):384-389.

110. Johnson BA, Jasinski DR, Galloway GP, et al. Ritanserin in the treatment of alcohol dependence - a multi-center clinical trial. Ritanserin Study Group. Psychopharmacology (Berl). 1996;128(2):206-215.

111. Naranjo CA, Poulos CX, Lanctôt KL, Bremner KE, Kwok M, Umana M. Ritanserin, a central 5-HT2 antagonist, in heavy social drinkers: desire to drink, alcohol intake and related effects. Addiction . 1995;90(7):893-905.

112. Wiesbeck GA, Weijers HG, Chick J, Naranjo CA, Boening J. Ritanserin in relapse prevention in abstinent alcoholics: results from a placebo-controlled double-blind international multicenter trial. Ritanserin in Alcoholism Work Group. Alcohol Clin Exp Res. 1999;23(2):230-235.

113. Maccioni P, Serra S, Vacca G, et al. Baclofen-induced reduction of alcohol reinforcement in alcohol-preferring rats. Alcohol. 2005;36(3): 161-168.

114. Flannery BA, Garbutt JC, Cody MW, et al. Baclofen for alcohol dependence: a preliminary open-label study. Alcohol Clin Exp Res. 2004;28(10):1517-1523. 
115. Addolorato G, Caputo F, Capristo E, et al. Baclofen efficacy in reducing alcohol craving and intake: a preliminary double-blind randomized controlled study. Alcohol Alcohol. 2002;37(5):504-508.

116. Addolorato G, Leggio L, Ferrulli A, et al. Effectiveness and safety of baclofen for maintenance of alcohol abstinence in alcohol-dependent patients with liver cirrhosis: randomised, double-blind controlled study. Lancet. 2007;370(9603):1915-1922.

117. Leggio L, Ferrulli A, Zambon A, et al. Baclofen promotes alcohol abstinence in alcohol dependent cirrhotic patients with hepatitis $\mathrm{C}$ virus (HCV) infection. Addict Behav. 2012;37(4):561-564.

118. Addolorato G, Leggio L, Ferrulli A, et al. Dose-response effect of baclofen in reducing daily alcohol intake in alcohol dependence: secondary analysis of a randomized, double-blind, placebo-controlled trial. Alcohol Alcohol. 2011;46(3):312-317.

119. Garbutt JC, Kampov-Polevoy AB, Gallop R, Kalka-Juhl L, Flannery BA. Efficacy and safety of baclofen for alcohol dependence: a randomized, double-blind, placebo-controlled trial. Alcohol Clin Exp Res. 2010;34(11):1849-1857.

120. McBride WJ, Lovinger DM, Machu T, et al. Serotonin-3 receptors in the actions of alcohol, alcohol reinforcement, and alcoholism. Alcohol Clin Exp Res. 2004;28(2):257-267.

121. Sellers EM, Toneatto T, Romach MK, Somer GR, Sobell LC, Sobell MB. Clinical efficacy of the 5-HT3 antagonist ondansetron in alcohol abuse and dependence. Alcohol Clin Exp Res. 1994;18(4): 879-885.

122. Johnson BA, Roache JD, Ait-Daoud N, Zanca NA, Velazquez M. Ondansetron reduces the craving of biologically predisposed alcoholics. Psychopharmacology (Berl). 2002;160(4):408-413.

123. Johnson BA, Roache JD, Javors MA, et al. Ondansetron for reduction of drinking among biologically predisposed alcoholic patients: a randomized controlled trial. JAMA. 2000;284(8):963-971.

124. Myrick H, Anton RF, Li X, Henderson S, Randall PK, Voronin K. Effect of naltrexone and ondansetron on alcohol cue-induced activation of the ventral striatum in alcohol-dependent people. Arch Gen Psychiatry. 2008;65(4):466-475.

125. Simpson TL, Saxon AJ, Meredith CW, et al. A pilot trial of the alpha-1 adrenergic antagonist, prazosin, for alcohol dependence. Alcohol Clin Exp Res. 2009;33(2):255-263.
126. Fox HC, Anderson GM, Tuit K, et al. Prazosin effects on stress- and cueinduced craving and stress response in alcohol-dependent individuals: preliminary findings. Alcohol Clin Exp Res. 2012;36(2):351-360.

127. McKee SA, Harrison EL, O'Malley SS, et al. Varenicline reduces alcohol self-administration in heavy-drinking smokers. Biol Psychiatry. 2009;66(2):185-190.

128. Mitchell JM, Teague CH, Kayser AS, Bartlett SE, Fields HL. Varenicline decreases alcohol consumption in heavy-drinking smokers. Psychopharmacology (Berl). 2012;223(3):299-306.

129. Penetar DM, Toto LH, Farmer SL, et al. The isoflavone puerarin reduces alcohol intake in heavy drinkers: a pilot study. Drug Alcohol Depend. 2012;126(1-2):251-256.

130. Lukas SE, Penetar D, Su Z, et al. A standardized kudzu extract (NPI-031) reduces alcohol consumption in nontreatment-seeking male heavy drinkers. Psychopharmacology (Berl). 2013;226(1):65-73.

131. Bujarski S, O’Malley SS, Lunny K, Ray LA. The effects of drinking goal on treatment outcome for alcoholism. J Consult Clin Psychol. 2013;81(1):13-22.

132. Maisel NC, Blodgett JC, Wilbourne PL, Humphreys K, Finney JW. Meta-analysis of naltrexone and acamprosate for treating alcohol use disorders: when are these medications most helpful? Addiction. 2013;108(2):275-293.

133. Lewis B, Nixon SJ. Characterizing gender differences in treatment seekers. Alcohol Clin Exp Res. Epub August 9, 2013.

134. Chamorro AJ, Marcos M, Mirón-Canelo JA, Pastor I, GonzálezSarmiento R, Laso FJ. Association of $\mu$-opioid receptor (OPRM1) gene polymorphism with response to naltrexone in alcohol dependence: a systematic review and meta-analysis. Addict Biol. 2012;17(3): 505-512.

135. Johnson BA, Seneviratne C, Wang XQ, Ait-Daoud N, Li MD. Determination of genotype combinations that can predict the outcome of the treatment of alcohol dependence using the 5-HT(3) antagonist ondansetron. Am J Psychiatry. 2013;170(9):1020-1031.
Substance Abuse and Rehabilitation

\section{Publish your work in this journal}

Substance Abuse and Rehabilitation is an international, peer-reviewed, open access journal publishing original research, case reports, editorials, reviews and commentaries on all areas of addiction and substance abuse and options for treatment and rehabilitation. The manuscript management system is completely online and includes a very quick and fair

\section{Dovepress}

peer-review system. Visit http://www.dovepress.com/testimonials.php to read real quotes from published authors. 